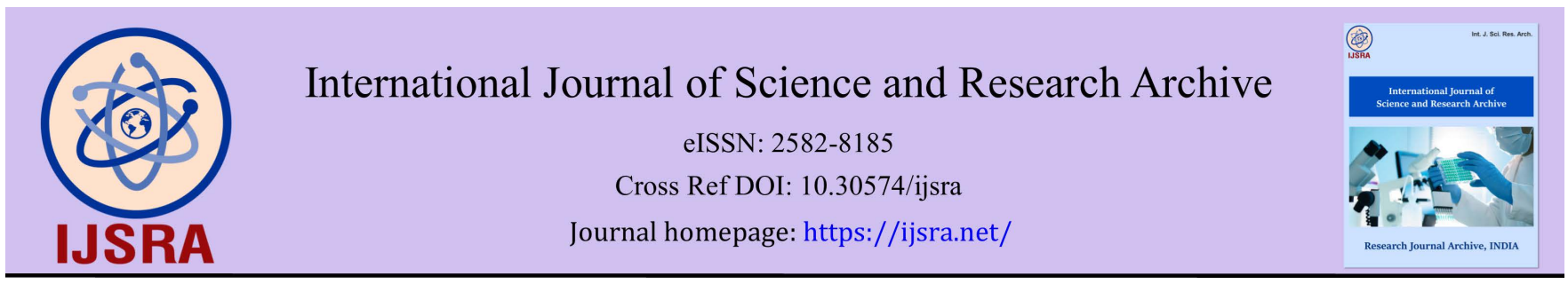

(RESEARCH ARTICLE)

Check for updates

\title{
The effect of some insecticides on the larvae of Aedes aegypti in Jeddah Governorate, Makah Province, Kingdom Saudi Arabia
}

\author{
Mohi Eldin Abdallah M Mohammed ${ }^{1}$, Omar Yousof M Ali ${ }^{2}$, Ashraf Abd El-Salam H Mangoud ${ }^{3}$ and Mutaman \\ Ali A Kehail 4,* \\ ${ }^{1}$ BNNICD, University of Gezira, Sudan. \\ 2 Faculty of applied medical sciences, Albaha University, Saudi Arabia. \\ ${ }^{3}$ Plant Protection Research Institute, Dokki, Egypt. \\ ${ }^{4}$ Faculty of Science, University of Gezira, Sudan.
}

International Journal of Science and Research Archive, 2021, 03(02), 043-048

Publication history: Received on 07 August 2021; revised on 16 September 2021; accepted on 18 September 2021

Article DOI: https://doi.org/10.30574/ijsra.2021.3.2.0128

\begin{abstract}
Mosquitoes can act as vectors for many disease-causing viruses and parasites through carrying these organisms from person to person. The objective of this study was to evaluate the susceptibility of Aedes aegypti larvae to some insecticides in Jeddah Governorate. Mosquito larvae were collected from all the available breeding sites in Jeddah municipalities using standard larval collection kits. The diagnostic doses (LC50 and LC90) were calculated from the mortality and concentration data. The larvicides Pirimiphos methyl, Fenitrothion, Bifenthrin and Cypermethrin were tested against the larvae of $\mathrm{Ae}$. aegypti mosquito. The results showed positive correlation between the concentrations under investigation and mortality\% of the treated larvae. Cypermethrin gave strong effect against Ae. aegypti larvae ( $\mathrm{LD}_{50} 0.0015 \mathrm{ml} / \mathrm{L}$ ) followed by Pirimiphos methyl (LD $\mathrm{LD}_{50} 0.0020 \mathrm{ml} / \mathrm{L}$ ), Bifenthrin (LD $\mathrm{L}_{50} 0.039 \mathrm{ml} / \mathrm{L}$ ), and at last rank Fenitrothion $(0.041 \mathrm{ml} / \mathrm{L})$. The same trend was obtained in LD90s. Ae. aegypti in Jeddah was susceptible to Bifenthrin, Cypermethrin, Pirimiphos methyl and Fenitrothion. Further studies should be run to conduct an intensive and appropriate vector control program in Jeddah Governorate.
\end{abstract}

Keywords: Clove pods; Phytochemistry; GC-MS; Mosquitoes; Natural products

\section{Introduction}

Mosquitoes (Diptera: Culicidae) are members of a group of about 3,500 species [1]. Mosquitoes are found everywhere, except Antarctica and from below sea level to elevation of 3,000 m or more. The majority of mosquito species fall into three groups: anophelines, culicines and aedines [2]. Mosquitoes can be an annoying, serious problem in man's domain. Mosquito-borne diseases are responsible for a significant fraction of the global disease burden and also on socioeconomic development of affected nations [3]. Larviciding largely depends on the use of synthetic chemical insecticides but it disrupted natural biological control agents and resulting in the development of resistance [4].

One of the most successful methods for mosquito control is the use of insecticides. However, long-term use of insecticides has resulted in the development of resistance in mosquito populations [5]. Protection from mosquito bites could be achieved by avoiding physical contact with mosquitoes. In order to solve the problem caused by insecticides to mammals and to find environmentally friendly control method, some natural products has been used to reduce the reliance on pesticide. This compound has generally been regarded as safe, but adverse effects when misapplied can be severe [6]. To avoid these harmful effects, several researchers are now focusing on the repellent qualities of products

${ }^{*}$ Corresponding author: Mutaman Ali A Kehail

Faculty of Science, University of Gezira, Sudan.

Copyright (c) 2021 Author(s) retain the copyright of this article. This article is published under the terms of the Creative Commons Attribution Liscense 4.0. 
derived from natural plant extracts. This work has recently led to a number of essential oils being recommended as mosquito repellents due to their eco-friendly and biodegradable nature [7].

In Jeddah Governorate, community participation is an important component of Ae. aegypti control strategies, through the elimination of water container breeding-sites in the domestic and pre-domestic area and environmental sanitation programs. However, community action alone may not be sufficient for the control of these vector populations since some breeding-sites could be neglected by the actions of environmental sanitation programs, making other intervention forms necessary, such as chemical control.

The objective of this work was to explore for the optimum and valuable control agent from different and modern formulations of larvicides, in order to conduct an intensive and appropriate vector control program in Jeddah Governorate.

\section{Material and methods}

\subsection{Study Area}

The study was conducted in Jeddah City (21032N and 39 $10 \mathrm{E})$, Makah province, Saudi Arabia. It is situated on the coast of the Red Sea and, as home to about 3.5 million people, is considered to be the major urban area of western Saudi Arabia. According to Jeddah Health Affairs, Ministry of Health, this area reports the highest incidence of mortality and morbidity in Jeddah.

\subsection{Mosquito Collection, Identification and Rearing}

Mosquito larvae were collected from all the available breeding sites in the study area (Jeddah municipalities) using standard larval collection kits. The collected larvae were identified and separated from predators. The collected larvae were transferred in the same day of collection to the Insectary (Public Health Pests Laboratory, Jeddah Municipality). During the rearing period, the larvae were fed on fish food. A few numbers of emerged adults were selected randomly for morphological identification using morphological features according to the identification key for common mosquito adults.

\subsection{Larval bioassays}

The diagnostic doses (LC50 and LC90) were calculated from the mortality and concentration data. The $3^{\text {rd }}$ instar larvae of Ae. aegypti was used to evaluate the susceptibility of the laboratory strains following WHO [8] instructions.

\subsection{Insecticides used}

- Synthetic ops larvicides: Pirimiphos methyl 50\% EC and Fenitrothion 50\% EC.

- Synthetic Pyrethroids larvicides: Bifenthrin 10\% EC and Cypermethrin 10\% EC.

\subsection{Statistical analysis}

Mortality percentages were corrected and calculated for natural mortalities by Abbott's [9]. The dosage mortality data were subjected to Probit analysis according to Finney [10]. The tested compounds were compared for their efficiency on insecticides according to their $\mathrm{LC}_{50}, \mathrm{LC}_{90}$ and slopes of the toxicity lines and statistical parameters.

\section{Results and discussion}

\subsection{Primiphos methyl and Fenitrothion}

Primiphos methyl (at $0.00125-0.005 \mathrm{ml} / \mathrm{L}$ ) and Fenitrothion (at $0.0156-0.25 \mathrm{ml} / \mathrm{L}$ ) were tested under laboratory conditions against Ae. aegypti larvae. The larval mortality\% of Primiphos methyl ranged between $20-97.5 \%$ in laboratory strain, while larval mortality\% of Fenitrothion ranged between $25-96.5 \%$ in laboratory strain (Table 1 and Figure 1). The results showed positive correlation between the concentrations under investigation and mortality $\%$ of the treated larvae.

The results showed that Pirimiphos methyl gave high effect against Ae. aegypti larvae ( $\left.\mathrm{LD}_{50} 0.002 \mathrm{ml} / \mathrm{L}\right)$. The same trend was obtained in LD90s, which was $0.0038(\mathrm{ml} / \mathrm{L})$ for Primiphos methyl, whereas Fenitrothion gave low effect against $A e$. 
aegypti larvae ( $\left.\mathrm{LD}_{50} 0.041 \mathrm{ml} / \mathrm{L}, \mathrm{LD}_{90} 0.113 \mathrm{ml} / \mathrm{L}\right)$. The results indicated that, Ae. aegypti in Jeddah was susceptible to Pirimiphos methyl and Fenitrothion.

Table 1Susceptibility of Ae. aegypti mosquito larvae to Primiphos methyl and Fenitrothion after 24 hours under laboratory conditions in Jeddah Governorate

\begin{tabular}{|c|c|c|c|c|c|c|}
\hline \multirow[b]{2}{*}{ Insecticide } & \multirow{2}{*}{$\begin{array}{l}\text { Effective } \\
\text { conc. } \\
(\mathrm{ml} / \mathrm{L})\end{array}$} & \multirow{2}{*}{$\begin{array}{l}\text { Larval } \\
\text { Mortality } \\
(\%)^{a}\end{array}$} & \multicolumn{4}{|c|}{ Statistical parameters } \\
\hline & & & $\begin{array}{l}\mathrm{LC}_{50} \\
(\mathrm{ml} / \mathrm{L})\end{array}$ & $\begin{array}{l}\mathrm{LC}_{90} \\
(\mathrm{ml} / \mathrm{L})\end{array}$ & Slope & $\mathbf{R}^{2}$ \\
\hline \multirow{5}{*}{$\begin{array}{l}\text { Primiphos } \\
\text { methyl }\end{array}$} & 0.0012 & 20.0 & \multirow{5}{*}{0.0020} & \multirow{5}{*}{0.0038} & \multirow{5}{*}{5.1} & \multirow{5}{*}{0.77} \\
\hline & 0.0015 & 25.0 & & & & \\
\hline & 0.0023 & 40.0 & & & & \\
\hline & 0.0038 & 65.0 & & & & \\
\hline & 0.0050 & 97.5 & & & & \\
\hline \multirow{5}{*}{ Fenitrothion } & 0.0156 & 25.0 & \multirow{5}{*}{0.041} & \multirow{5}{*}{0.113} & \multirow{5}{*}{2.19} & \multirow{5}{*}{0.85} \\
\hline & 0.048 & 42.5 & & & & \\
\hline & 0.068 & 57.5 & & & & \\
\hline & 0.083 & 70 & & & & \\
\hline & 0.250 & 97.5 & & & & \\
\hline
\end{tabular}

The obtained results did not agree with those obtained by Ponlawatm et al. [11], whom found that Ae. aegypti from all study sites were resistant to permethrin, but were susceptible to malathion. Resistance to temephos was detected in all strains of Ae. aegypti, except those from Nakhon Ratchasima. Ae. Albopictus larvae had low levels of resistance to all three insecticides, except Mae Sot and Phatthalung strains, which were resistant to permethrin.

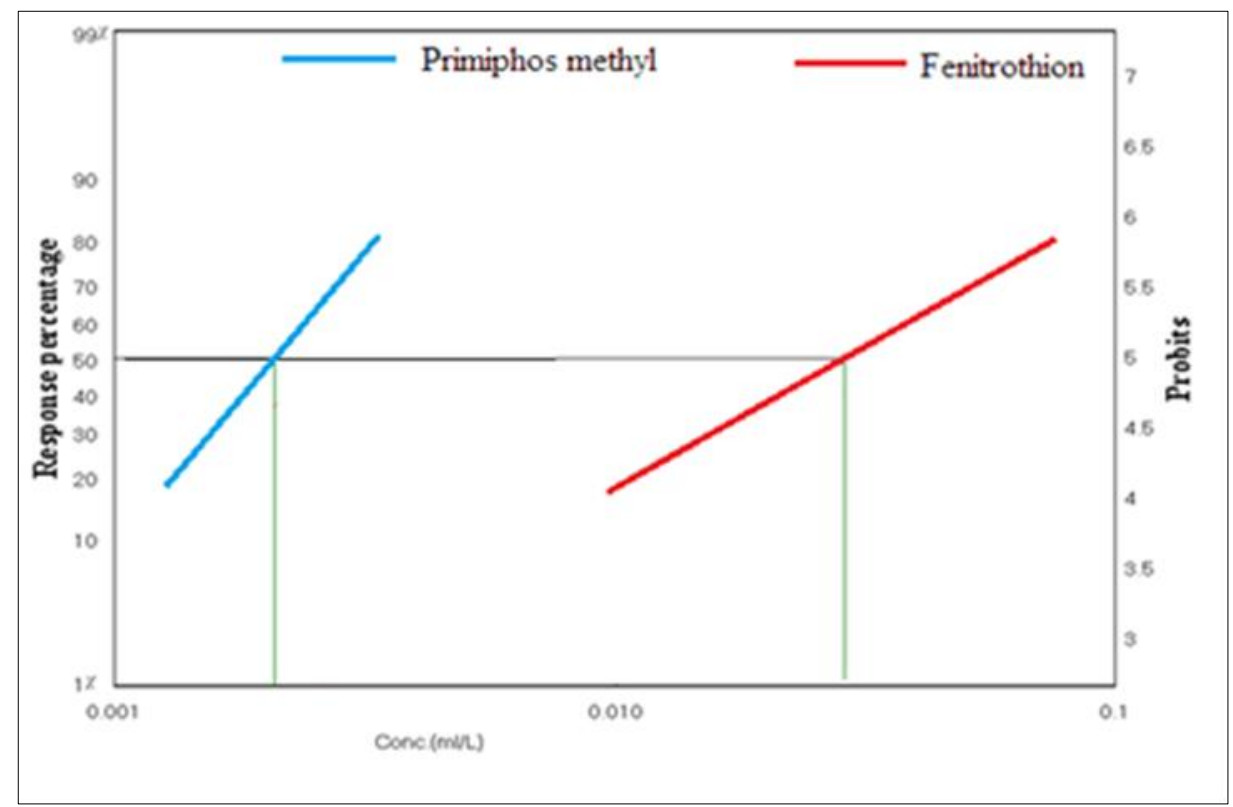

Figure 1LC-P lines of Primiphos methyl and Fenitrothion against larvae of Ae. aegypti under laboratory conditions in Jeddah Governorate 
The obtained results are agreed with those obtained by Rodríguez et al. [12] evaluated organophosphate insecticide resistance, including temephos, malathion, fenthion, methyl pirimiphos, fenitrothion and chlorpyriphos against Ae. aegypti larvae from Cuba and other Latin-American countries. They found all of the Ae. aegypti strains temephos resistance $\left(R_{50}>10 x\right)$, except for the Nicaragua strain which exhibited moderate resistance to this OP (RR between 5 and 10x), with a value of 9.1x. The highest RR value to temephos was (89.9x) in the Havana city strain followed by Costa Rica (68.3x), Jamaica (42.5x), Panama (23.3x), Peru (22.5x) and Venezuela (13.1x). Also found Ae. aegypti larvae were susceptible to malathion in all of the strains, and similar results were obtained for fenthion and fenitrothion.

\subsection{Bifenthrin and Cypermethrin}

Bifenthrin (at 0.015-0.24 ml/L) and Cypermethrin (at 0.0005-0.0312 ml/L) were tested under laboratory conditions against Ae. aegypti larvae. The larval mortality\% of Bifenthrin ranged between 20-97.5\%, while larval mortality\% of Cypermethrin ranged between $22.5-97.5 \%$ (Table 2). The results showed positive correlation between the concentrations under investigation and mortality\% of the treated larvae (Table 2 and Figure 2). The results showed that Bifenthrin gave high effect against Ae. aegypti larvae (LD $50.039 \mathrm{ml} / \mathrm{L}$ ), whereas Cypermethrin gave strong effect against $A$ e. aegypti larvae (LD $0.0015 \mathrm{ml} / \mathrm{L}$ ). The same trend was obtained in LD 90 s. The result indicated that, Ae. aegypti in Jeddah was susceptible to Bifenthrin and Cypermethrin.

The obtained results did not agree with those obtained by Sirisopa and Thanispong [13] they found Ae. aegypti from different localities in Thailand were strongly resistant to bifenthrin, permethrin and deltamethrin. High resistance to lambda-cyhalothrin was detected from all localities with the exception of Ae. aegypti from Bangkok and Uttaradit which demonstrated incipient resistance.

Table 2 Susceptibility of Ae. aegypti mosquito larvae to Bifenthrin and Cypermethrin after 24 hours under laboratory conditions in Jeddah Governorate

\begin{tabular}{|c|c|c|c|c|c|c|}
\hline \multirow[b]{2}{*}{ Insecticide } & \multirow{2}{*}{$\begin{array}{l}\text { Effective } \\
\text { conc. } \\
(\mathrm{ml} / \mathrm{L})\end{array}$} & \multirow{2}{*}{$\begin{array}{l}\text { Larval } \\
\text { Mortality } \\
\text { (\%) }\end{array}$} & \multicolumn{4}{|c|}{ Statistical parameters ${ }^{b}$} \\
\hline & & & $\begin{array}{l}\mathrm{LC}_{50} \\
(\mathrm{ml} / \mathrm{L})\end{array}$ & $\begin{array}{l}\mathbf{L C}_{90} \\
(\mathrm{ml} / \mathrm{L})\end{array}$ & Slope & $\mathbf{R}^{2}$ \\
\hline \multirow{5}{*}{ Bifenthrin } & 0.015 & 20.0 & \multirow{5}{*}{0.0389} & \multirow{5}{*}{0.1015} & \multirow{5}{*}{3.07} & \multirow{5}{*}{0.92} \\
\hline & 0.033 & 35.0 & & & & \\
\hline & 0.051 & 55.0 & & & & \\
\hline & 0.095 & 77.5 & & & & \\
\hline & 0.240 & 97.5 & & & & \\
\hline \multirow{5}{*}{ Cypermethrin } & 0.0005 & 22.5 & \multirow{5}{*}{0.0015} & \multirow{5}{*}{0.0086} & \multirow{5}{*}{1.68} & \multirow{5}{*}{0.89} \\
\hline & 0.0011 & 37.5 & & & & \\
\hline & 0.0023 & 55 & & & & \\
\hline & 0.0221 & 80 & & & & \\
\hline & 0.0312 & 97.5 & & & & \\
\hline
\end{tabular}

Generally, the larger the $\mathrm{R}^{2}$ indicates the greater the homogeneity of results [14]. Results in Table (2) indicated that the calculated $\mathrm{R}^{2}$ reached 0.92 and0.89, respectively, for Bifenthrin and Cypermethrin, while it were 0.77 and0.85forPrimiphos methyl and Fenitrothion, respectively.

The obtained results not agree completely with those obtained by Sirisopa and Thanispong [13] they found strong resistance to bifenthrin, permethrin and delta methrin was observed in all field test populationswhereasalphacypermethrinandcypermethrindemonstratedincipientornoresistance.

On the other hand, in Thailand studies have reported that there has been an increased deltamethrin resistance in several field populations of Ae. aegypti $[15,16]$. The increased incidence of resistance is raising awareness of the need for alternative insecticides or newer, more innovative methods of controlling mosquito vectors. Alpha-cypermethrin, 
another synthetic pyrethroid, is being used in Thai homes for protection against indoor biting mosquitoes and other arthropod pests.

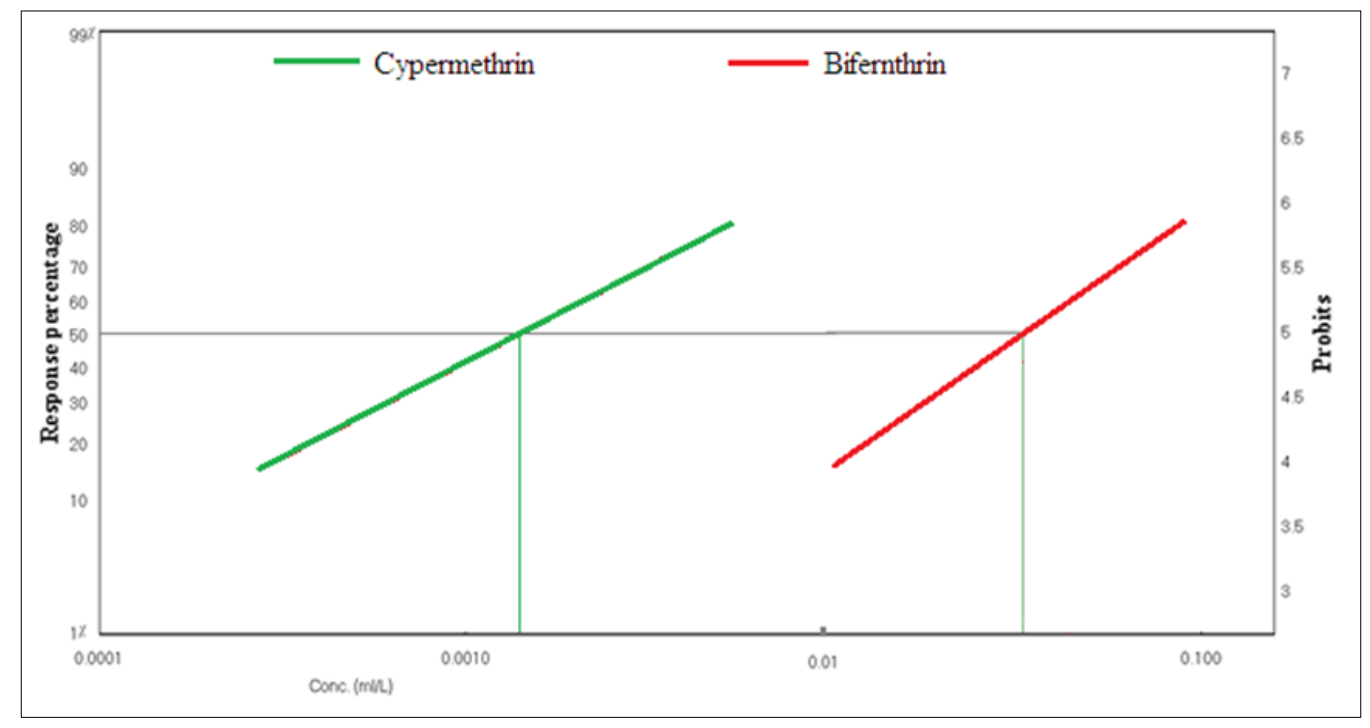

Figure 2LC-P lines of Bifenthrin and Cypermethrin against larvae of Ae. aegypti under laboratory conditions in Jeddah Governorate

\section{Conclusion}

All results showed positive correlation between the concentrations under investigation and mortality\% of the treated larvae. Cypermethrin gave strong effect against Ae. aegypti larvae ( $\mathrm{LD}_{50} 0.0015 \mathrm{ml} / \mathrm{L}$ ) followed by Pirimiphos methyl $\left(\mathrm{LD}_{50} 0.0020 \mathrm{ml} / \mathrm{L}\right)$, Bifenthrin ( $\left.\mathrm{LD}_{50} 0.039 \mathrm{ml} / \mathrm{L}\right)$, and at last rank Fenitrothion $(0.041 \mathrm{ml} / \mathrm{L})$. The same trend was obtained in LD90s. Ae. aegypti in Jeddah was susceptible to Bifenthrin, Cypermethrin, Pirimiphos methyl and Fenitrothion.

\section{Compliance with ethical standards}

\section{Acknowledgments}

Thanks, are for the staff of the Insectary of the Public Health Pests Laboratory, Jeddah Municipality; and Blue Nile National Institute for Communicable Disease, University of Gezira for their academic advice and technical support.

\section{Disclosure of conflict of interest}

The authors (MohiEldin; Omar; Ashraf and Mutaman) declare no conflicts of interest regarding the publication of this paper.

\section{Statement of ethical approval}

The present research work does not contain any studies performed on animals/ humans subjects by any of the authors.

\section{References}

[1] Harbach R. Family Culicidae Meigen, 1818. Mosquito Taxonomic Inventory. 2008.

[2] Eldridge BF. Biology of disease vectors. 2nd edition, Dana Dreibelbis. 2005; 95-96.

[3] WHO. Integrated Vector Management: Strategic Framework for the Eastern. The Mediterranean Region 20042010. The WHO Regional Office, Cairo. 2004.

[4] Hedlin PA, Holingworth RM, Masler EP, Miyamoto J, Thopson DG. Phytochemicals for pest control. ACS SympSer No. 658. Washington DC: American Chemical Society. 1997. 
[5] Misni N, Sulaiman S, Othman H, Omar B. Repellency of essential oil of Piper aduncum against Aedes albopicctus in the laboratory. J Am Mosq Contr Assoc. 2009; 25: 442- 447.

[6] Yang P, Ma Y. Repellent effect of plant essential oils against Aedes albopictus. J Vector Ecol. 2005; 30: 231- 234.

[7] Adeniran OI, Fabiyi E. A cream formulation of an effective mosquito repellent: a topical product from lemongrass oil (Cymbopogon citrates Stapf). J Nat Prod Plant Resour. 2012; 2: 322- 327.

[8] WHO. Monitoring and managing insecticide resistance in Aedes mosquito populations. Interim guidance for entomologists. WHO, Geneva. 2016.

[9] Abbott WS. A method of computing the effectiveness of an insecticide. J Econ Entomol. 1925; 18: 265-267.

[10] Finney DJ. Probit Analysis: A Statistical Treatment of the Sigmoid Response Curves. 3rded. Cambridge, UK: Cambridge University Press. 1971.

[11] Ponlawatm A, Scott JG, Harrington LC. Insecticide Susceptibility of Aedes aegypti and Aedes albopictus across Thailand. J Med Entomol. 2005; 42(5): 821-825.

[12] [12] Rodríguez MM, Bisset J, Fernandez D. Levels of insecticide resistance and resistance mechanism in Aedes aegypti from some Latin American countries. J American Mosquito Control Association, 2008, 23(4):420-429.

[13] [13] Sirisopa P, Thanispong K. Resistance to Synthetic Pyrethroids in Aedes aegypti (Diptera: Culicidae) in Thailand. Kasetsart J (Nat Sci), 2014, 48: 577-586.

[14] Kehail MAA, Basheir NHH. Susceptibility of Anopheles arabiensis Patton and Culex quinquefasciatus Say larvae to selected insecticides and some natural products in Wad Medani, Sudan. 2nd National Pest Management Conference in the Sudan (NPMC). 2004; 56-57.

[15] Jirakanjanakit N, Rongnopharut P, Saengtharatip S, Chareonviriyaphap T, Dunchon S, Bellec L. Insecticide susceptible/resistance status in Aedes (Stegomyia) aegypti and Aedes (Stegomyia) albopictus (Diptera: Culicidae) in Thailandduring 2003-2005. J Econ Entomol. 2007; 100: 545-550.

[16] Chuaycharoensuk T, Juntarajumnong W, Boonyuan W, Bangs MJ, Akratanakul P, Thummapalo S, Jirakanjanakit N, Tanasinchayakul S, Chareonviriyaphap T. Frequency of pyrethroid resistance in Aedes aegypti and Aedes albopictus (Diptera: Culicidae) in Thailand. J Vector Ecol. 2011; 36: 204-212. 